\title{
WHO guidelines challenged in Botswana: traditional medicine between healing, politics and witchcraft
}

\author{
Klaus Geiselhart ${ }^{1}$ \\ University of Erlangen-Nuremberg, Germany
}

\begin{abstract}
The World Health Organization (WHO) supports integrating traditional health care into national health systems. The reasons why this is not happening in Botswana are manifold, complex and not always rational. Traditional healers demand the right to practice their techniques and organize themselves with an emancipatory political claim, but they are unsuccessful. Based on a political ecology of health perspective combined with assemblage thinking, this article explores discourses and historical lines of development in order to show how Christian morality, the dualism between tradition and modernity and the introduction of a modern public health system are intertwined with belief in witchcraft that clandestinely hampers development.
\end{abstract}

Keywords: political ecology, medical epistemes, public health, traditional healing, witchcraft, assemblage

\section{Résumé}

L'Organisation mondiale de la santé (OMS) suggère d'intégrer les soins de santé traditionnels dans les systèmes de santé nationaux. Les raisons pour lesquelles cela ne se produit pas au Botswana sont multiples, complexes et pas toujours rationnelles. Les guérisseurs traditionnels revendiquent le droit de pratiquer leurs techniques et de s'organiser avec une revendication politique émancipatrice, mais ils ne réussissent pas. Basé sur une perspective d'écologie politique de la santé combinée à la pensée d'assemblage, cet article explore les discours et les lignes de développement historiques. L'objectif est de montrer comment la morale chrétienne, le dualisme entre tradition et modernité et l'introduction d'un système de santé publique moderne sont intimement liés à la croyance en la sorcellerie. Cela entrave le développement de manière clandestine.

Mots-clés: écologie politique, épistémèmes médicaux, santé publique, guérisons traditionnelles, sorcellerie, assemblage

\section{Resumen}

La Organización Mundial de la Salud (OMS) apoya la integración de la asistencia médica tradicional a los sistemas nacionales de salud. Las razones por las que no sucede aún en Botswana son variadas, complejas y no siempre racionales. Quienes practican la medicina tradicional demandan su derecho de practicar sus técnicas y organizarse de acuerdo a una declaración política emancipatoria, sin aún tener éxito. Desde una perspectiva de la ecología política de la salud en combinación con un pensamiento basado ensamblajes, este artículo explora discursos y líneas históricas de desarrollo con el fin de demostrar cómo la moralidad cristiana, el dualismo entre la tradición y la modernidad, y la introducción de un sistema moderno de salud pública, están entrelazados con creencias y hechicería que, de manera clandestina, obstruyen el desarrollo.

Palabras clave: ecología política, epistemes médicos, salud pública, medicina tradicional, hechicería, ensamblaje

\section{Introduction}

According to the 2002 World Health Organization strategy on traditional medicine (TM), alternative healing practices should be integrated into national health systems. This is not only because some countries might otherwise fail to introduce nationwide access to public health services, but also because alternative

\footnotetext{
${ }^{1}$ Dr. Klaus Geiselhart, Institute of Geography, University of Erlangen-Nuremberg, Wetterkreuz 1591052 Erlangen,
} Germany. Email: klaus.geiselhart "at" fau.de. Thankyou to two referees. 
healing has been found to be gaining acceptance all over the world (WHO 2002: 2). In developing countries, accessibility, affordability, and the fact that traditional health services are firmly embedded in belief systems are seen as the main factors propelling such popularity. To ensure safety and rational use, the WHO has called for the development of national and international regulations, standards and guidelines. Many countries have already established a legal basis for cooperation between their national health systems and practitioners of complementary medicine, leaving Botswana as one of the last countries in southern Africa where such a process is still pending (WHO 2002:17, own research).

This article examines the background to this delay, the complexity of which can be illustrated by the following statements. According to local WHO representative Moagi Gaborone who emphasizes the local variety of traditional healing, "traditional medicine is a very broad area. It's very difficult to come up with a definition that covers the whole area [...] of this practice" (27/08/2012). Botswana's Ministry of Health blames "the lengthy of consultative processes" and emphasizes, in addition to a technical question on the registration of practitioners, the difficulties of determining the field of application: "please note that there are number of practices of this kind of service although they do not readily agree that they belong to the same category" (Email statement MOH 16/05/2014). Officially, the problem is a question of definition. However John P. Setilo, president of the Baitseanape ba Setso mo Botswana (Association of Traditional Healers), offers a different explanation: "Some officers, because of their religious beliefs, [...] don't feel comfortable with letting such a bill go through. [...] People tend to equate witchcraft to the practice of traditional medicine" (25/02/2014). Setilo sees hypocrisy practiced by people who live modern lifestyles and pretend not to have faith in traditional belief systems or medicine, but who still consult a healer for assistance with relationship problems, bad luck, or economic hardship. Setilo states that even some politicians will consult healers, especially when looking for a means of winning election campaigns. These statements open up broader issues and questions. The seemingly simple question "what is traditional healing?" leads deep into highly complex debates that touch on colonial history, political discourses and questions of global hegemony in the field of medical knowledge.

Despite healers calling themselves 'traditional doctors', the term has historically developed as a category to differentiate them from 'modern doctors.' Anthropologists including Murray Last have often questioned the significance and discriminatory power of this dualistic distinction (e.g. Last 1986). However, in order to understand the current political discourse in Botswana it is necessary to see that this distinction is deeply institutionalized in the practices that govern and perform health care. Political positions are based on this distinction, and in public discourses it is permanently reproduced.

Many of the misunderstandings that exist between modern doctors and traditional healers stem from the fact that they each assume that the other side shares their understanding of basic concepts. In the following, the term "healing" will be used to show that the respective notions of such fundamental concepts can only be made comprehensible to members of the other school of healing in dialectical comparison. To this end, it is important to look at the genealogy of the relationship between both schools of medical knowledge and to see the development of health care as a history of actual people and places (Jackson and Neely 2015; King 2010).

This leads us into a dialectical distinction. From studying "knowledge" we come to those convictions or lores that are regarded ill-founded or unsubstantiated. We enter the realm of beliefs which, as again anthropologists tell us, cannot be clearly distinguished from that of knowledge (Last 1986). From here we have to address questions of religion, and we encounter prejudices and moral convictions. The dialectic of good and evil appears when spiritual healing is associated with witchcraft. "Both healers and witches draw their powers from three possible sources: inheritance of abilities from ancestors; training by skilled masters; and direct communication with higher powers such as the ancestors or spirits" (Leister 2014: 55).

Witchcraft is a real practice, but it is clandestine and seldom publicly discussed. In special cases, however, it is even recognized by law. "It has been held both in Botswana and in South Africa that a belief in witchcraft in certain communities is a factor which does materially bear upon an accused's moral blameworthiness" (Criminal case record 1998). However, it is assumed that only uneducated people believe in witchcraft, or use witchcraft. It would "not be an extenuating circumstance if the accused was an academic member of a literate, vastly intelligent and highly educated university community" (idid.). But this assumption 
contradicts empirical evidence, for example when a young, well-trained entrepreneur in Gaborone says: "Witchcraft is there. It is everywhere" (interview 22/04/2017).

Section two explains how assemblage approaches can complement political ecology to describe such social environments of entangled elusive belief systems, political discourses and everyday beliefs. Assemblage approaches try to grasp the complexity and diversity of localized cultural conditions, which cannot be captured by a single consistent narrative. Accordingly, thinking in assemblages will be explored through its implications for academic writing. Subsequently, on the basis of a reflection on the global hegemony of modern medicine, the article develops the manifold relationships between historical developments, actual practices, moral convictions and systems of belief or knowledge that characterize the politics of traditional healing, and that ultimately hamper important developments within the health care sector in Botswana.

\section{Methods and perspectives}

In order to understand the "asymmetric communication" between modern medicine and local systems of health and healing, it is necessary to consider how different schools of medicine have become positioned and naturalized in the triad of ideas, practices and institutions (Naraindas, Quack and Sax 2014: 4). Accordingly, a perspective on local health politics is needed. Recent approaches in political ecology employ a multitude of methods in order to facilitate a historical approach displaying the contingency and entanglement of different political positions within a local environmental context (Connolly, Kotsila and D'Alisa 2017; Jackson and Neely 2015).

Latour (2004) shows that political ecologies often implicitly presuppose a dualism between politics and nature, thus concealing the fact that what is regarded to be 'nature' is already constructed by politics dividing humankind and the environment. In order to overcome this shortcoming, Latour (2005) suggests not to strictly adhere to academic disciplines, but rather to empirically follow the connections that human or non-human actors create and through which they establish networks. "Analysis should not assign scales or units of analysis in advance but rather follow the actor into multiple scalar exercises" (Tsing 2010: 49). This article traces 'traditional healing' along the junctions revealed during fieldwork.

This article takes the concept 'environment' a little further than usual and also includes symbolic orders of the social, such as discourses on 'traditional healing' and 'witchcraft.' Such orders influence the perception of people, but they can hardly be fixed on clear and unambiguous content. 'Indigenous' worlds of meaning are mainly handed down and negotiated orally and there are no explicit original sources that could be used as references. Accordingly, it is not suitable to establish ideas of what 'traditional healing' or 'witchcraft' are—or once might have been-but rather to offer a perspective on the dynamics that evolve when these terms come into play.

Inspired by assemblage approaches (Dewsbury 2011; McFarlane and Anderson 2011), the article collates my own empirical data, media reports, statements from strategy papers, anthropological findings, theological and epistemological reflections, as well as arguments of public discourses such that an assemblage of opinions, convictions, beliefs, political positions and interests become vivid. Some transitions between levels or scales—from local to global, individual to societal, past to present, or theoretical to empirical —might appear abrupt but are necessary to display links within current praxis.

Conventional academic narratives usually fail to portray praxis in its complexity and diversity of perspectives. They usually depend on their own selectivity and create conditions that disregard everything that does not contribute to a consistent logical end. Academic narratives that present themselves as products of ironclad rational consequentiality are illusions that neglect the fact that all objects or entities always emerge from the perspective of a critical mind (Dewey 1929). As already indicated, the subject of the present study is also particularly distinguished by the fact that the main objects of investigation mutually define each other. Whether it is 'tradition' and 'modernity', 'knowledge' and 'belief' or 'Africa' and 'the West', each of these categories co-constitute their respective binary counterpart. They are only significant in coexistence. However, this does not happen once and conclusively, but is carried out continuously, always in singular ways, always under new practical conditions, in diverse contexts. If this peculiarity of social praxis is taken into account the definitions of the empirical analysis must also become fluid. Therefore, this article does not offer any 
unambiguous definitions. A style of writing that does justice to assemblage thinking tries to avoid the deceptive illusion of ostensible clearness which oversimplifying rationality produces. Rather, it displays co-existence whereby objects can only be defined in their dissociation of each other. A collage creates an intuitive order in which the fragments gain significance through their proximity or relative position to each other (Dewsbury 2011; McFarlane and Anderson 2011).

The article is based on a review of literature from various applied and scientific areas and presents empirical data from fieldwork. Between 2004 and 2017, the author conducted research on health issues in Botswana. The aim was to analyze the entire spectrum of local health services. Investigations on the national health system were carried out mainly in the years 2004 to 2007. The main research on traditional medicine took place between 2011 and 2014. A series of short visits between and after the main campaigns served to complete missing data, examine preliminary results and follow up further lines of inquiry. In interviews, representatives of the WHO, the Ministry of Health and some churches were asked to express their views on traditional healing and their opinions about why there is still no legal traditional health policy. Private individuals were asked about their perception of healers and witchcraft and three group discussions were held with participants from different socio-economic backgrounds. One conversation with young, wealthy guests took place in the lounge of a lodge in Gaborone, another was held with the guests of a private party in a marginalized township and the third was conducted with young men in a local rural bar. By means of a radio broadcast on GabzFM it was possible to collect further opinions about witchcraft among the urban dwellers of Gaborone. Online editions of local newspapers were searched for reports referring to witchcraft and the Botswana e-law database was searched for protocols that provide clues on how courts deal with witchcraft.

In addition to intensive reading of anthropological studies, ethnographic methods were also used to gain a more multi-faceted understanding of traditional healing methods in Botswana. A total of 16 healers were interviewed, who were selected initially by means of snowball sampling and later on by theoretical sampling. ${ }^{2}$ They were interviewed in several places, five in the city or suburbs of Gaborone, the rest in rural communities. Three of the latter lived in very remote places. Some healers were studied more intensely by repeated interviews and through participant observations. Rituals, consultations and the collection of medicinal plants were observed; the researcher was introduced to some basic healing techniques. These ethnographic methods provided fundamental insights into the multiplicity of emic views. Representatives of established healers' associations were interviewed about the experience they made during negotiating the planned legal policy on traditional medicine with government authorities. Within the limited scope of this article, little of this data can be presented. However, it is possible to give an insight into the very enmeshment of the politics of regulating traditional healing methods. With the exception of public figures, names in this article are anonymized.

\section{Political ecology, epistemology and the contestation of hegemonic discourses}

Political ecology focuses on human-environment interactions from a perspective of political economy. Health care interests and power relations are subject to investigation in order to critically analyze inequalities in healthy living conditions, and in access to resources such as health services. Such power relations are shaped by discourses (Connolly, Kotsila and D'Alisa 2017; King 2010). In order to compare the different positions in the field of health services, it is therefore necessary to "deconstruct the knowledge we produce as we work to understand health" (Jackson and Neely 2014: 2).

Hegemonic discourses in the realm of medicine do not only determine which ideas are valid knowledge and which receive the status of beliefs. Different medical epistemes also draw different boundaries between humankind and the environment. In modern medicine, the human body is seen as the interface between mind and environment. Instead, traditional doctors in Botswana see a continuity in which human individuals are connected through social, physical and spiritual bonds. In this understanding, it is impossible to isolate the human body from emotions and ideas, and healing focuses on influencing attributions of meaning as well as

\footnotetext{
${ }^{2}$ In theoretical sampling of Grounded Theory, interview partners are selected on the basis of theoretical considerations. Who takes a complementary perspective, and could inform aspects of research aspects that may not have been discussed so far?
} 
the character of relationships. However, if the question of the human condition gets a different answer, then the term 'environment' automatically also takes on a different meaning. A political ecology of health, which takes this idea seriously, thus becomes a political epistemology, which examines what claims and interests are associated with what perceptions of humankind (see also Porto 2017).

In a Foucauldian perspective, power is inscribed in hegemonic discourses of which two can be identified as exercising power over traditional healing in Botswana, that of modern medical knowledge and the morality of Christianity. However, such disposifs are by no means static, but are constantly challenged and stabilized.

The One, the All, the True, the object, the subject are not universals, but singular processes - of unification, totalisation, verification, objectivation, subjectification - present in the given apparatus. (Deleuze 1992: 162)

How powerful a certain discourse is depends on how naturalized it is, how deeply it has influenced general understandings of the population. In the global North, the biomedical understanding of disease is omnipresent.

The historical fact we have to face is that in modern Western society biomedicine not only has provided a basis for the scientific study of disease, it has also become our own culturally specific perspective about disease, that is, our folk model. (Engel 1977: 130)

In addition, biomedicine is an export hit for good reason, as in cases of certain diseases it bears the ability to save many lives. Biomedicine has established a global hegemony.

Assemblage approaches extend beyond analyzing hegemonic discourses and focus also on processes of discourse contestation. In the present case, it is therefore necessary to take into account other ideas about the human condition in order to achieve a more-than-biomedical perspective from which those medical perspectives, which were empirically found in praxis, can also be evaluated. Such understanding can be found in the concept of salutogenesis (Antonovsky 1996) or the biopsychosocial model of illness influenced by findings of psychoneuroimmunolgy (Engel 1977). Both concepts reject the body-mind dichotomy as a final concept. As the biopsychosocial model is based on a theory of complexity, it also rejects the pathogenetic principle of cause and effect as the sole factor determining the development of illnesses. Pauls (2013) argues that this framework challenges clinical research methodology and therapy approaches to such an extent that a change of paradigms is necessary, with currently unclear implication and consequences. The biopsychosocial model demands that doctors regard patients in the full constellation of their environments, social relationships and paths through life.

Such more-than-biomedical concepts are often associated with spiritual healing methods such as those found in many traditional, religious or alternative approaches to health, for example shamanism (Kirmayer 2004; Money 2001; Winkelmann 2013). Similarities are obvious. In many alternative understandings of healing there is a transcendent instance described as a kind of wholeness, cosmology or general integrity. Accordingly, if a holistic assessment of the patient is required, then rationality, which is prone to categorization and fragmentation, might be less helpful than spiritual techniques, which intuitively try to crystallize the problem of the client out of the infinite multiplicity of possibly health threatening factors.

However, efficacy of spiritual healing techniques can hardly be scientifically proven and the WHO is well aware of this fact (WHO 2002: 21). Accordingly, the WHO aims to ensure safety, efficacy, quality and the rational use of traditional medicine (WHO 2002: 5). However, these quality criteria are by no means universally valid, but also are derived historically in the wake of scientific thinking (Daston and Galison 1992). The situation is thus somewhat absurd. On the one hand, the WHO has advocated for a long time a comprehensive approach to health. "Health is a state of complete physical, mental and social well-being and not merely the absence of disease or infirmity" (WHO 1948). However, at the same time, the WHO is aware that a purely biomedical approach can at best serve for illness prevention but by no means meets the requirements of good 
health promotion. Nevertheless, there is no clear idea of which approach is necessary for putting more-thanbiomedical understandings into practice. Public health systems have developed historically parallel to the emergence of biomedicine and the pathogenic principle is thus still a fundamental concept in most of their practices.

Accordingly, the WHO and national authorities concentrates on controlling the surrounding conditions of traditional healing which makes traditional healers feel patronized. In his role as a representative of a healer organization, Setilo sums up the feelings of many healers:

We are working closely with the Ministry of Health. That I would admit. But we are working closely with them, not as equal partners really, because at the end of the day all they do is to run workshops for us, for purposes of wanting us to help solve their problems. They concentrate maybe on HIV/AIDS. Nowadays there is diarrhoea. So they will workshop us on diarrhoea. And that's it. $(18 / 08 / 2012)$

Like Setilo, many other healers expressed the opinion that the authorities are not interested in establishing cooperation on an equal footing, but that they want to enforce biomedical knowledge.

\section{Traditional healers and politics}

It is essential to see that emphasizing 'tradition' on the one hand is necessary so that healers can claim a form of unity of their profession. In addition, the term 'traditional medicine' is commonly used and thus has a certain intuitive plausibility. On the other hand, the term is opaque because it is not clear what 'tradition' means. Generally, when characterizing their understanding, interviewed healers vaguely referred to native religious and spiritual conceptions, tradition, and tribal culture. However, this is a broad area of beliefs and practices.

Usually, healers explained that they developed their healing powers individually through spiritual intuition and empirical observations (cf. Thornton 2009). Dreams, visions and spiritual connections to ancestors were often mentioned and one healer even said that he was taught solely by natural spirits such as snakes. The field of traditional healing is therefore extremely individualized and diverse, in contrast to modern medicine, which is believed to be highly standardized due to health care regulations. Gaborone:

So one of the issues the parliamentarian wanted clarified was what exactly, when you say traditional medicine, what do you mean? (National Professional Officer WHO: 27/08/2012)

At the moment, there is apparently no definition that could adequately answer this question for the requirements of modern public health administrations. Instead, the reference to 'culture' is omnipresent, for example when a traditional pharmacy advertises with the slogan "we specialise in culture", when healers in the interviews refer to tribal culture, and associations of traditional healers use 'culture' to advocate their practices and to claim rights. The emphasis on culture is also prevalent when the umbrella organization for traditional healing practitioners calls itself "Baitseanape ba Setso mo Botswana" which means "experts in culture of Botswana."

The preservation of 'tradition' or 'culture' can be a powerful argument in political contexts, for example for the Shuar shamans in South America, who "have even become central figures in the politics of ethnicity and in antidevelopment protests" (Joralemon 2001: 14034, cf. Johnson 1995). However, in Botswana, this argument does not apply so strongly, grounded perhaps in the history of the country. During the colonial period, the area of present-day Botswana had a certain local autonomy. Under the leadership of the chiefs of the main Tswana tribes, it has developed peacefully from its status as a British protectorate to a modern democracy. Traditional authorities have been given a legal role in the constitution through the establishment of a house of chiefs. Most political authorities today, especially those of the leading Botswana Democratic Party, understand themselves as tradition-conscious but also progressively modern. Botswana is also driven by an intrinsic desire for 
modernization. Against the background of the immense success of the modern health care system, the emphasis of the healers on 'culture' may in a negative sense seem backwardly oriented to many people.

There are interesting historical traces of a progressing marginalization of traditional healers. In precolonial times, dingaka (singular: ngaka) were highly appreciated by the tribal leaders (Duke 2014). "The chief knew every ngaka within his region and would call upon them for various purposes - as healers, advisors, religious specialists, and assistants for throwing the bones to find the guilty party in cases of witchcraft accusations" (Ingstad 1990: 31). There are many factors that have contributed to these bonds being massively weakened. The competition between Christian missionaries and dingaka in defining the divine is often seen as central (Dube 2014). As many tribal chiefs took on the Christian faith, so-called 'prophet healers' (porofeti) also began to worship and spiritually consult the Christian God in addition to their ancestors and the Tswana God (modimo).

In the interviews, all healers showed a more or less distinct tendency to justify themselves by declaring in one way or another that their practices do not contradict Christian morality. They recounted syncretistic narratives. For example, one healer claimed that Jesus was obviously an ancestor, since he appeared to his followers after his death. Another healer explained that once healers on a ship, in a heavy storm, had been advised by their divining bones to throw Jonah overboard. By sending Jonah back on his mission, the healers' spirituality finally helped to realize the divine plan. Healers also refer to the traditional ethics of botho or ubunto to explain that their world views do not contradict Christianity. Botho/Ubunto is a metaphysical idea of the interdependence of all beings in the universe. The common phrase "a person is a person through other persons" expresses the social core of this ethic (Metz and Gaie 2010: 274). Botho/Ubunto contains the moral obligation to perceive oneself as being connected with others and to take on responsibility for the well-being of others. Recent theological works point out analogies between botho/ubunto and Christian morality, concluding that "according to the Botho worldview, one can never be a Christian or attain salvation a se na Botho (without Botho)" (Mmualefhe 2007: 26). In theology, the long-standing antagonism between tradition and Christianity can be bridged today, but this understanding has by no means become established in everyday practices in Botswana.

However, back to the question of how traditional medicine could be defined. The two most important emic terms used to describe healers in Botswana are 'ngaka' (plural: dingaka) and 'sangoma' (plural: basangoma). Today, 'ngaka' is usually understood as herbal doctor while 'sangoma' indicates a spiritual healer. However, these interpretations have historical roots that are rarely recognized. They were mainly influenced by the Betchuanaland Protectorate administration, which only allowed healers herbs for treating illnesses. Practices that contained spirituality in some way (such as divining, fortune-telling, or trance dancing) were forbidden and branded as witchcraft, presumably because they were "incomprehensible and intolerable to western thinking" (Hedberg and Staugard 1989: 27). This basic evaluation of the Betchuanaland Protectorate administration witchcraft proclamation of 1927-which is still in legal force-was adopted by the Government of Botswana after independence in 1966: "The diviner, associated with the supernatural, must be eliminated, whereas the herbalist, concerned only with physical forms of healing, is to be granted the stamp of legitimacy" (Staugard 1986: 65).

However, during the fieldwork not even one 'ngaka ya ditshotshwa', who solely uses herbs for treatment without utilizing any form of spirituality, could be identified. All interviewees, both dingaka (10, of which one was a 'porofeti') and basangoma (6), reported that their training was essentially based on spirituality. The respective plural forms indicate probably the most important difference between dingaka and basangoma. The prefix "ba-" in Setswana indicates affiliation to a social category, such as a tribe or a group. Basangoma are organized in lodges or schools and after their training still are committed to the lineages of their training. In contrast, the prefix "di-" is an indefinite plural form indicating that each and every single ngaka stands for his or her individual healing powers.

\section{The spiritual sense of Tswana healing}

Recognizing that spirituality needs to be regarded as an essential element of traditional healing in Botswana was a basic insight emerging from the research. Most healers interviewed explained that they had 
received a calling, which forced them to seek training as a traditional doctor. They had either suffered from an illness that modern doctors were not able to cure, or had recurring dreams or visions. To varying degrees, they reported that trainers demanded that their trainees acquire knowledge about herbs and treatment mainly through spiritual intuition. In order to diagnose patients all healers employed oracles. These included a fancy apparatus, a calabash which turned under the fingers, holy water, various collections of objects such as shells, bones or stones, and a complex four tablet divining system which is standard amongst the basangoma.

In general, the dingaka and basangoma understand illness not solely as a bodily problem. All healers interviewed expressed a similar explanatory model of health and illness based on ancestral belief. In contrast to illness which is understood as resulting from disturbed relationships, health is seen as being in harmony with relatives, neighbors, the community, ancestors, and the environment. People can become spirits when they die. As spirits, they still have influence on those who are living and can bring about happiness, health, and prosperity but also death, sickness, misfortune, and poverty (cf. also Larson 1971; Amanze 2008). Ordinary people are not able to detect these influences nor can they counter or manipulate them. Healers are "seen as intermediaries between the living and the ancestral spirits (badimo)" (Ingstad 1990: 31).

In contrast to the modern understanding of disease, symptoms do not play a major role in indicating a traditional diagnosis. Healers commonly first decide whether a disease is a 'Tswana disease' or a 'modern disease.' In the latter case, the healer may refer the patient to the hospital or a nearby clinic (Ingstad 1990; Ulin 1975). "Patients who have been diagnosed by healers as having the same Tswana disease may differ considerably in their illness presentations, and similar symptoms may lead to quite different diagnoses depending on the social circumstances surrounding the illness episode" (Ingstad 1990: 32). Loneliness stirs up despair and hopelessness and reduces a person's resilience. Mistrust, envy and hostility make people sick.

Such understanding of health refers to botho/ubuntu, which also has far-reaching implications for consultation and treatment approaches. Dingaka and basangoma heal their clients by re-establishing sound relations within the spiritual and social fabric:

Whereas there is yet no cure, there is nonetheless healing. Botho brings about healing. [...] The miracle of a touch and the spirit of connectedness, even more than anti-retroviral drugs can help those infected to live a more meaningful life. Consequently, this would bring about healing and wholeness to the wider communitas. (Mmualefhe 2007: 14)

According to botho/ubuntu, one person's sickness is a concern for the whole community. A strong and supportive community needs to be provided for all individuals so that everyone can stay healthy or at least live a meaningful life despite an illness. This concept of 'healing' complements modern medicine's notion of 'cure' and the proximity to more-than-biomedical concepts seems obvious. In the past, however, traditional medicine was hardly considered capable of complementing modern medicine.

\section{Local historical traces of the hegemony of biomedicine}

Since colonial times, dingaka and basagoma experienced an increasing loss of influence as many local authorities converted to Christianity and the state-wide public health system proved to be relatively effective and successful. Attempts to install cooperation between traditional and modern health services have long since been intended (Chipfakacha 1994; WHO 1990). However, healers became marginalized. The discussion in the 1980s about the professionalization of African medicine tried to decipher why "healers have been left to practice as before, unregulated and unfunded by government" (Last 1986: 2). It was seen as problematic that traditional medicine in Africa hardly contained an explicit corpus of knowledge (Last 1986: 12).

After the year 2000, the successes of the modern health care system in Botswana became particularly visible because it proved to be very effective in the fight against AIDS. A global alliance of the government with a large private foundation, NGOs, private-sector actors and medical institutes fought HIV and AIDS through a massive intervention program. Under the pressure of high infection and mortality rates, there was a need for immediate relief. Due to the urgency of the problem, this program focused mainly on ensuring a basic 
supply of antiretroviral drugs. The measure was a typical development cooperation project, which was largely implemented by means of international expertise, so that modern and foreign knowledge intruded into local contexts.

Traditional healers had been concerned with the phenomenon of increasing deaths long before the modern intervention and even if they had no cure for it, their explanation of the disease in terms of local perceptions made sense of the phenomenon (Mmualefhe 2007; Rakelmann 2005; Tabalaka 2007). However, Tabalaka (2007) cites different authors who called traditional beliefs 'untrue' or 'mythical', arguing "there was a need for cultural change, given the fact that AIDS threatens to wipe out the population of Botswana. [...] We are in a war situation where we have to make many tough decisions and forget about some of our cultural beliefs in order to save millions of lives" (Tabalaka 2007: 63).

Spirituality contradicts the rationality of modern medicine and modern doctors often consider traditional healers to be irrational (Tabalaka 2007). However, the benefits of spiritual or community-oriented practices are widely unexplored. Research has mainly been done on traditional medicinal plants and has confirmed many of them to be effective (for Botswana, see Staugard 1989; Andrae-Marobela et al. 2010). In recent years biochemists have even found that some traditional herbs could significantly inhibit HIV-1 replication (Leteane et al. 2012). However, local political authorities refrain from honoring traditional medicine for such achievements, as the vice president Ponatshego Kedikilwe explained it in an opening remark at the National AIDS council:

We are aware and are concerned about reports that some traditional herbs have been shown to cure AIDS or even reduce chances of HIV infection. As a country, it would be unfortunate if we rushed to such options, as they have potential to take us where we were some 28 years back. (Kedikilwe 2013)

From the perspective of the national HIV/AIDS intervention, everything that diverges from the current practice of biomedical intervention might lead to lower acceptance of, and compliance with the ARV treatment scheme, and must thus appear as threatening the success of the national response. Modern doctors and public health administrators usually do not take traditional practitioners seriously. In addition, traditional healers are suspicious for another reason.

\section{The suspicion of witchcraft}

The perception formulated in the Betchuanaland Protectorate administration Witchcraft Proclamation of 1927 has entered common perception amongst the Batswana. According to Setilo, many people regard all engagement with spirits as witchcraft. Setilo:

Since the colonial era our people have been so brainwashed that they look at traditional medicine as witchcraft. And it is definitely not. (24/02/2014).

In interviews, people employing modern lifestyles often reproduced the colonial misunderstanding of spiritual and herbal treatment mentioned above. In a group discussion with young people at a respectable hotel garden, a young man explained. Theriso ${ }^{3}$ :

A ngaka, who apparently is a traditional doctor, is totally separate from a sangoma. You see, because one of them deals in spirit the other one deals in medicine which is traditional medicine from the trees, from the rocks, from the herbs and all that so that is a big difference. (16/3/2011)

\footnotetext{
${ }^{3}$ Anonymized.
} 
This one group interview reflects in many respects what could also be found in other conversations. Many respondents initially stated that they did not believe in witchcraft. For example, Theriso continued:

Witchcraft is not existent in the modern world. [...] That belief in the spirits and such sort of things, I mean it is not existent in the modern world right now. (16/03/2011)

In this exchange, the two young men agreed in interpreting ancestral beliefs as such: Dumisani ${ }^{4}$ :

What are you believing in that ancestors? Are you believing that they are going to come and heal your cough or are you believing they are coming to enhance your life? [...] Are you just respecting ancestors? Like for example we always respect our forefathers. (16/03/2011)

However, if you continue to involve people in a conversation, then resentment is usually exposed. These concerns originate from Christian beliefs and presuppose the existence of witchcraft. Dumisani:

The fact that they [traditional healers] can protect you means that they can bewitch somebody else. And that means... if you are talking about God and Jesus.... I mean if you are praying God. God is not supposed to harm your enemy. But them, they are harming enemies, isn't it? $(16 / 03 / 2011)$

Such a reaction on the topic of witchcraft is by no means unusual. In interviews with official representatives of organizations and authorities, the mention of witchcraft usually generated great scepticism. The respondents took the following stance; witchcraft is something one might have heard of, but not something you want to be associated with. The following interview with the National Professional Officer of the Gaborone WHO branch Moagi Gaborone is typical. First, he distances himself almost reflexively from knowing more about witchcraft. He said he would only know what was reported in the media. Then, however, he loses himself in some thoughts about traditional culture, until he immediately starts rowing back and almost apologizes for his digression. Gaborone:

I know a few cases of people [...]. These were like out in the open on TV, on radio in the papers, and that sort of things. Yah, there had been situations like that. I think the difficulty for that with conventional law is that it maybe something like very hard to be proven in the court of law. But in a traditional court, because you have people who represent the culture. I think it becomes easier for them to understand what the issues are and deal with them from a cultural, you know, perspective and that sort of things. [Suddenly he speaks faster and louder] But that has really nothing to do with us as WHO. [Stuttering] As a Motswana I was just sort of sharing some of these things. I guess we digressed a little bit. (27/08/2012)

Significantly, Botswana's Ministry of Health skillfully avoids the question of whether witchcraft discourses are a reason for the delay in establishing official regulations for cooperation between modern and traditional medicine: "The notion of associating traditional healing with witchcraft often stems from assertions these practitioners are able to cast spells on people. It is however held highly by traditionalists who believe in its power" (email statement MOH 16/05/2014). It seems as if the Ministry delimits 'traditionalism' from modern administration here. Official bodies do not deal with spiritual phenomena. For international agencies such as the UN, witchcraft, if not simply ignored as superstition, is often dealt with in terms of its most vicious effects - witch-killing and ritual murder. Of course, violence and witchcraft is an important field of research as outrageous human rights violations take place (e.g. Ashforth 1998; Hund 2000; WHRIN 2013).

\footnotetext{
${ }^{4}$ Anonymized.
} 
However, witchcraft is a much broader phenomenon. As it became clear that mystical ideas would not vanish in the wake of modernity, anthropologists rediscovered the topic in the 1990s. Contemporary beliefs about witchcraft have been shown to be highly diverse, deeply culturally embedded, and vividly applicable to actual situations. Witchcraft has been described as a reaction to modernity and globalization and appears as a resistance to hegemonic definitions of Western thought and modern regulation (Shores 1997: 7-9). Witchcraft is also regarded as a dubious means of gaining economic or political power (Harnischfeger 2000; Rowlands and Warnier 1988). Furthermore, there is an everyday dimension of witchcraft. Witchdoctors are often consulted for purposes such as fostering good luck, or spiritually bonding a partner in a relationship. This form of witchcraft concerns the nexus of close family relationships. Common aspects of relationships, such as jealousy, envy, resentment, or hostility are often still seen as an expression of bad spirits (Geschiere 1997: 912). In some contexts of life, the fear of evil spirits can be omnipresent (Ashforth 1998).

\section{Moral evaluations of witchcraft belief and practices}

Deciding to consult a traditional doctor depends on whether people are satisfied with their lives. Nonofo and Kabelo ${ }^{5}$, two young men attracted by modern lifestyles but struggling hard to establish a micro-business, said that they had consulted a traditional doctor due to personal crises. Nonofo:

Because my life was going upside down. Everything was going down. Yaa, everything was like ... eey was like damn. (09/03/2011)

The healer traced their problem back to witchcraft. Nonofo:

I was having these people who are after me. Who like changing my life from good to bad. Man! Relatives and everybody. I really saw that with my naked eyes. I found them doing that things, that traditional things, and everything. There at home. Man! Now, life has changed. I am living another life. Since I got help from him [healer]. (09/03/2011)

The healer's clients were convinced that he managed to banish negative spirits. The fact that Nonofo really identified a harmful social relationship in his private environment is less interesting, because his judgement may have been biased by the healer's statements. Rather, it is interesting that this social problem has not been solved by social intervention, for example by sanctioning the supposedly malicious relative, but by ritual application of muti (traditional medicine). Kabelo:

And guess what happens. After taking a bath with that portion of medicine that he gave us, we started to be having customers. Because our business was relatively new. 'We will be having a lot of customers coming.' Exactly what he told us. (09/03/2011)

Obviously, after the assessment of the social environment by the diagnosis, another re-evaluation has taken place through the ritual. The negative forces, wherever they came from, were obviously dispelled, without interfering with family circumstances. The naming of witchcraft as cause and trust in the healer solved the problem without anyone being officially charged or accused.

In the interviews, the majority of healers said that one of their major tasks is to avert the harmful effects of witchcraft. Setilo:

The traditional doctor's role is basically that of being antidote to witchcraft. [...] The traditional healer's role is to foster good health and good social well-being of people. (24/02/2014)

\footnotetext{
${ }^{5}$ Both anonymized.
} 
However, skepticism remains as the young people in the group discussion agreed. Kebitsemang ${ }^{6}$ :

One will tell you I am the good one. We all want to say we are good. You understand. But at the end of the day we fear a sangoma like we fear a traditional doctor in the society. No child will be allowed to play at the sangoma's yard. [...] We don't know who is doing what, where, how. [...] A whole of notions that we don't understand. And only that two groups will understand it better and they are not about to tell us their secret. (16/03/2011)

Despite the mental serenity that comes from dismissing witchcraft as irrational and ineffective mysticism, indefinite fears of potential unknown powers remain. Setilo even sees hypocrisy among people with modern lifestyles:

Our leaders will pretend that they don't believe in traditional medicine or whatever [...] There is a lot of hypocrisy. Look at it this way, elections are coming in 2014 and a good number of us will make a lot of money. Because the very same people who will be saying traditional medicine is rubbish blabla, will come running to us because they want muti to be reelected [...] There's a lot of hypocrisy. (18/08/2012)

During the fieldwork, various practices related to witchcraft were identified. For example, the author witnessed how one night in a very extensive ceremony an evil spell was removed from a plot of land. An old woman had served as a medium for the healer Gaone ${ }^{7}$. After ritual cleansing of the attendants, she dug in the earth with her bare hands, which had been loosened up by a pickaxe and mixed with glowing coals. Finally, she brought out a small bottle, the muti, the witch medicine. At the same moment she fell to the ground in a trance and her ancestors spoke through her with distinctly different voices. The healer talked to all these voices and so he was informed about the background and origin of the muti. Finally, the muti was made harmless by cooking a pigeon in its blood with a mixture of herbs and the participants washing themselves with this mixture. Thus the evil influence was sent back to its originator. According to the healer, she now had to expect severe illness or even death (Participatory observation 01/04/2011).

Asked if it wouldn't have been immoral to return the spell, Gaone said in a later conversation: "According to the bible's principles yes, but not to our doctors. In our tradition, the ancestors want us to fight back. They are angry and they come and give us the knowledge" (Interview 09/04/2011). To prevent witchcraft from becoming too powerful, the people who practice it would have to be discouraged. He further explained that porofeti (prophet healers) would not retaliate, they would dispose of witch spells differently, by burning them or simply by throwing them away.

In order to produce a medicine that causes general misfortune and illness, a personal object belonging to the target person is necessary, such as a small shred of that person's clothes. This item is mixed with special herbs and animal blood, filled into a container or laced into a small bundle. In order for this witch medicine to become effective, it must be hidden close to the person targeted or buried on their property. Such muti is also sometimes found in football stadiums, where it is intended to harm one particular team in favor of another (Mmegi-online 29/11/2011). One healer described a similar ritual with which one can bind people together, e.g. one's partner, and another healer described a different ritual to avoid court cases. For the latter purpose they drive deep into the savannah with the client, who has to wash him or herself with a mixture of herbs according to given rules.

These opinions about traditional healers expressed in the group interviews indicate that the question of whether something is to be judged as healing or witchcraft is usually decided along a moral dividing line

\footnotetext{
${ }^{6}$ Anonymized.
}

${ }^{7}$ Anonymized. 
between good and evil. Other interviews with healers and individuals have raised questions about the benefits and harms of certain practices. How is it possible to distinguish harmful practices from health-promoting practices, especially when it comes to creating economic success or happiness? What helps the client may harm another person, and you may not even know this person. Even healers admitted that they once found it difficult to distinguish between healing and witchcraft. Every healer must draw this line for him- or herself. Gaone ${ }^{8}$, for example, says that he is committed only to the client. Accordingly, he offers practices that others would not use. However, this seems to have been less a conscious moral decision on his part than a path-dependency that has developed from his economic situation and the wishes of his clients. Gaone presents himself as a determined fighter against witchcraft, but in the interviews he avoided being specific about the boundary between healing and witchcraft.

Unlike Gaone, Sipiwe ${ }^{9}$, a healer who practices in the underprivileged township of Old Naledi in Gaborone, tries hard not to be associated with witchcraft. Sipiwe is known for his excellent healing powers. Every time he offers consultations in Old Naledi, about ten to twelve people sit in front of his house waiting their turn to be seen. Sipiwe is a small man with a round face and a very friendly appearance. He is benevolent, but at the same time determined and assertive. He uses a unique oracle for diagnosis: a mechanical device that can be moved like a wooden limb snake. By its movement, the apparatus answers questions or gives hints, similar to a divining rod, which helps to detect desired things. When asked why so many people consult him, he did not mention his extraordinary healing powers. He said he was focusing exclusively on alleviating pain. Sipiwe explained that his only interest is in relieving his clients from their ailments, and any suspicion that he might be involved in witchcraft would stop his patients from coming (interview 27/05/2011).

Gaone and Sipiwe illustrate the range of possible moral justifications used to defend traditional healing practices. Most of the healers interviewed had decided to practice their spirituality as secretly as possible. Two dingaka said they were hiding their spiritual work, in fear of being accused of witchcraft. One healer kept even the fact that he was a sangoma secret and only practiced in his home village. In his normal place of residence he was a teacher at a primary school and feared discrimination in the workplace. In short, it can be said that the fear of being associated with witchcraft places a heavy burden on most healers.

\section{Witchcraft as a cultural world view}

Witchcraft is often seen as an alliance with evil powers. This idea of witchcraft can lead to witch-hunts and witch killings, for which there are numerous examples worldwide (WHRIN 2013). But fraternization or obsession with evil is neither the sole nor predominant concept in witchcraft. Gaborone's city dwellers held a whole spectrum of different views. A radio broadcast on GabzFM gave the opportunity to ask the listeners whether they felt that witchcraft should receive more attention in public debate. Different ideas about witchcraft were described. Of course, it was displayed as a dangerous evil power but also, for example, as an outdated, harmful faith or as an amusing superstition. Witchcraft has also been declared a genuine African understanding of the world: "I think witchcraft is science. People who are practicing witchcraft are intelligent and only them knows it all" (audience opinion from 12/04/2017). This opens up an anthropological dimension to witchcraft that touches the essence of cultural world views, and the construction of knowledge in cultural belief systems.

The so-called 'rationality debate' in anthropology revolves around the question of how religious beliefs, especially in Africa, can be explained. Stambach (1999) concludes that all world views or ontologies, regardless of whether they are called magic or scientific, are intended to control human experiences and predict the outcomes of social dealings by proposing causal relations. However, these world views control reality not because they represent elementary truths but rather because they guide behavior in everyday life. Belief systems thus acquire prognosis, and in this sense "in traditional African culture, magic fulfils the role that science plays in modern society" (Leistner 2014: 55; cf. Thornton 2009). Accordingly, mysticism and witchcraft are not only to be judged negatively. Positive aspects can also be identified. For example, belief in witchcraft can ensure equality and justice within a community by regulating the negative effects of human attitudes such as jealousy,

\footnotetext{
${ }^{8}$ Anonymized.
}

${ }^{9}$ Anonymized. 
avarice, envy or hostility. Ironically, healers are forced to conceal such characteristics, which are an essential basis of their medicine, in their everyday practices.

Leistner identifies scholars who "emphasise that the reality of the spirit world and magic practices are central to African life and culture. They show that witchcraft is an integral feature of African identity and belongs to the common cultural heritage of all Africans" (Leistner 2014: 54). While this is an anthropological view, it is not reflected in national health planning or international policy where magic is equated with superstition, mysticism or unscientific irrationality. UN policy stresses certain specific effects of witchcraft beliefs, namely the massive human rights violations that are committed, for example, in cases of ritual murders or when people are accused of witchcraft (WHRIN 2013). African imaginaries, especially those about traditional Africa, illustrate what could be called Western logocentrism. Wiredu argues for a conceptual decolonization, which "consists in an African's divesting his thought of all modes of conceptualisation emanating from colonial past that cannot stand the test of due reflection" (Wiredu 2004: 15). In particular, the following concepts require investigation: 'reality', 'entity', 'truth', 'fact', 'faith', and 'knowledge.'

Witchcraft can be understood as a method of perceiving the world, to which botho/ubunto offers the corresponding conception of the world and ethics. Recently, scholars have not only described the proximity of this ethics to Christian morality (Mmualefhe 2007), but have also demonstrated its advantages in other areas of society, such as jurisprudence (Cornell and Muvangua 2012) and education (Letseka 2013). In addition, as already explained, its implications for healthcare (Jenson and Gaie 2010) are in line with the discoveries of more-than-biomedical perspectives on health, which have also been developed in Western societies due to increasing criticism of pure biomedicine. Furthermore, traditional ideas also converge with the latest findings in scientific medicine. There are many reasons to acknowledge the epistemological foundations of traditional health systems (Naraindas, Quack and Sax 2014) and magic and witchcraft are often closely linked to traditional medical schools. Even if spiritual concepts are hardly compatible with concepts of modern thinking, they are worth being recognized by public health authorities and health organizations.

\section{Conclusion}

Two major hegemonic discourses, biomedicine and Christian morality, frame the social environment in Botswana and thus also the context for current health policy. Under current socio-political conditions, traditional healers are forced to juggle several arguments. They have to launch statements into an indeterminable sphere of common-sense discourses, prejudices and stereotypes to defend what they do. However, their messages are not destined to hover weightlessly. They must be constantly intercepted and revised so that they do not collapse to the ground faced with the reproaches of those opposed to traditionalism, mysticism and witchcraft.

Healer organizations present themselves as experts in traditional culture in order to advocate their claims. This emphasis is ambiguous, however, as the term 'traditional medicine' historically emerged as a category to distinguish healers from modern doctors. On the one hand, it is not possible to avoid the term because it is in common use, and its strength is that in a rough sense it will always be intuitively understood. On the other hand, the term is nothing more than a very imprecise outline. It is opaque and does not specify any particular quality or benefit. It ultimately reproduces a colonial distinction that perpetuates long-standing resentment. In addition, the emphasis on tradition as in opposition to modernization does not help to formulate a powerful political argument in Botswana, because the influence of the West and modernity has brought many developments perceived as positive.

Modern scientific rationales and Christian morality suppress witchcraft discourses only superficially. Witchcraft is not just a myth. The mere fact that it is actually practiced, consulted and feared makes it a social reality. Witchcraft and magic are integral parts of African epistemologies, and while their existence is not denied, they are marginalized. They are assigned a realm in society which is addressed as traditionalism, connoted as backward-looking and often evaluated by perceptions that derive from Christianization. Witchcraft is even more opaque than 'tradition.' It can be approached as an assemblage of deeply entangled processes advocating tradition against modernity, good against bad, and with an emphasis on social life opposed to the hegemony of modernity. 
'Africa' and the 'West' are "two categories have become mutually defining in that both are born historically and culturally out of the other" (Stambach 1999:350). Since this fact permeates every attempt to talk about traditional healing, the topic can barely be grasped by the category-based systematics in the official administrative logic guiding modern health authorities. Since spiritual practices are based on a completely different episteme than modern science, it is difficult to regulate such practices by using standards derived from modern understanding, as the WHO actually attempts to do. Traditional healers in Botswana therefore feel patronized by such a modern attempt to control their business. What is called cooperation appears to them as indoctrination or reschooling.

Given this complex situation, it is understandable that Botswana is thinking carefully about how traditional healing can be integrated into the national health system, as the WHO suggests it should be. However, it seems as if these processes have, unfortunately, come to a standstill. Whatever one might think of witchcraft, whether it is considered as superstition or mysticism, at least it seems powerful enough to inhibit health care developments that seem beneficial from the WHO's rational point of view. The integration of traditional health care into Botswana's national health system requires a conceptual decolonization of basic categories of hegemonic discourse. At the moment, the two schools of thought can hardly be integrated rationally. Their perceptions of the human condition are so different that they seem incommensurable. One way forward could be to develop mediating concepts that build bridges between the two medical epistemes.

\section{Bibliography}

Amanze, J.N. 2008. Christianity and ancestor veneration in Botswana. Studies in World Christianity 9(1): 4359.

Andrae-Marobela, K., B.N. Ngwenya, K.N. Monyatsi, H. Okatch and M. Muzila 2010. Documentation and promotion of indigenous knowledge-based solutions for Botswana - an ethnosurvey. CESRIKI Research Report. Gaborone: Center for Scientific research, Indigenous Knowledge and Innovation, University of Botswana.

Antonovsky, A. 1996. The salutogenic model as a theory to guide health promotion. Health Promotion International 11(1): 11-18.

Ashforth, A. 1998. Witchcraft, violence, and democracy in new South Africa. Cahiers d'études africaines 38(150-152): 505-532.

Chipfakacha, V. 1994. The role of culture in primary health care. South African Medical Journal 84(12): 860862.

Criminal case record. 1998. PUSO v. THE STATE 1998 BLR 421 (CA). Online: http://www.elaws.gov.bw/ (accessed 26/4/2017).

Connolly, C., P. Kotsila, and G. D'Alisa. 2017. Tracing narratives and perceptions in the political ecologies of health and disease. Journal of Political Ecology 24: 1-10.

Cornell, D. and M. Muvangua. 2012. Ubuntu and the law: African ideals and post-Apartheid jurisprudence. New York: Fordham University Press.

Daston, L. and P. Galison. 1992. The image of objectivity. Representations 40: 81-128.

Deleuze, G. 1992. What is a dispositif? In T.J. Armstrong (ed.) Michel Foucault, philosopher: essays translated from the French and German. New York: Harvester Wheatsheaf. Pp. 159-168.

Dewey, J. 1929. Experience and nature. London: Allen \& Unwin.

Dewsbury, J-D. 2011. The Deleuze-Guattarian assemblage: plastic habits. Area 43(2): 148-153.

Dube, M.W. 2014. Translating Ngaka: Robert Moffat rewriting an indigenous healer. Studia Historiae Ecclesiasticae 40(1): 157-172.

Engel, G.L. 1977. The need for a new medical model: a challenge for biomedicine. Science 196(4286): 129136.

McFarlane, C. and B. Anderson. 2011. Thinking with assemblage. Area 43(2): 162-164. 
Geschiere, P. 1997. The modernity of witchcraft: politics and the occult in postcolonial Africa. Charlottesville: University of Virginia Press.

Harnischfeger, J. 2000. Witchcraft and the state in South Africa. Anthropos 95(1): 99-112.

Hedberg, I. and F. Staugard. 1989. Traditional medicine in Botswana: traditional medicinal plants. Gaborone: Ipelegeng Publishers.

Hund, J. 2000. Witchcraft and accusations of witchcraft in South Africa: ontological denial and the suppression of African justice. The Comparative and International Law Journal of Southern Africa 33(3): 366-389.

Ingstad, B. 1990. The cultural construction of AIDS and its consequences for prevention in Botswana. Medical Anthropology Quarterly 4(1): 28-40.

Jackson, P. and A.H. Neely. 2015. Triangulating health: toward a practice of a political ecology of health. Progress in Human Geography 39(1): 47-64.

Jenson, K. and J. Gaie. 2010. African communalism and public health policies: the relevance of indigenous concepts of personal identity to HIV/AIDS policies in Botswana. African Journal of AIDS Research 9(3): 297-305.

Johnson, P.C. 1995. Shamanism from Ecuador to Chicago: a case study in new age ritual appropriation. Religion 25: $163-178$.

Joralemon, D. 2001. Shamanism. In Smelser, N.J. and P.B. Baltes (eds.) International Encyclopedia of the Social and Behavioral Sciences. Oxford: Oxford University Press. Pp. 14032-14035.

Kedikilwe, P. 2013. Opening remarks by His Honour the vice president Dr. Ponatshego Kedikilwe at the National AIDS Council. http://www.gov.bw/globalassets/naca-ministry/wana/opening-remarks-by-vpnac----25-april-2013.pdf, Gaborone, 17/10/2013.

King, B. 2010. Political ecologies of health. Progress in Human Geography 34(1): 38-55.

Kirmayer, L.J. 2004. The cultural diversity of healing: meaning, metaphor and mechanism. British Medical Bulletin 69: 33-48.

Larson, T.J. 1971. The spirits of the ancestors and the Mandengure ceremony of the Hambukushu of Ngamiland. Anthropos 66(1/2): 52-70.

Last, M. 1986. The professionalisation of African medicine: ambiguities and definitions. In Last, M. and G.L. Chavunduka (eds.) The professionalisation of African medicine. Manchester: Manchester University Press: 1-19.

Latour, B. 2004. Politics of nature: how to bring the sciences into democracy. Cambridge: Harvard University Press

Latour, B. 2005. Reassembling the social: an introduction to Actor-Network-Theory. Oxford: Oxford University Press.

Leistner, E. 2014. Witchcraft and African development. African Security Review 23(1): 53-77.

Leteane, M. M., B.N. Ngwenya, M. Muzila, A. Namushe, J. Mwinga, R. Musonda, S. Moyo, Y. Mengestu, B.M. Abegaz and K. Andrae-Marobela. 2012. Old plants newly discovered: Cassia sieberiana D.C. and Cassia abbreviata Oliv. Oliv. root extracts inhibit in vitro HIV-1c replication in peripheral blood mononuclear cells (PBMCs) by different modes of action. Journal of Ethnopharmacology 141(1): 4856.

Letseka, M. 2013. Educating for Ubuntu/Botho: lessons from Basotho indigenous education. Open Journal of Philosophy 3(2): 337-344.

Metz, T. and J. Gaie. 2010. The African ethic of Ubuntu/Botho: implications for research on morality. Journal of Moral Education 39(3): 273-290.

Mmegi-online. 2011. Two men caught with 'muti' at UB Stadium. Allegations of 'muti' use in local football have surfaced once again. http://www.mmegi.bw/index.php?sid=8\&aid=280\&dir=2011/November/Tuesday29/ Mmegi-online 29/11/2011. 
Mmualefhe, D.O. 2007. Botho and HIV \& AIDS: a theological reflection. In J.B.R. Gaie and K.M. Sana (eds.) The concept of Botho and HIV and AIDS in Botswana. Eldoret: Zapf Chancery Publishers Africa. Pp. 1-27.

Money, M. 2001. Shamanism as a healing paradigm for complementary therapy. Complementary Therapies in Nursing and Midwifery 7(3): 126-131.

Naraindas, H., J. Quack and W.S. Sax. 2014. Entangled epistemes. In Naraindas, H., J. Quack and W.S. Sax (eds.) Asymmetrical conversations: contestations, circumventions, and the blurring of therapeutic boundaries. New York: Berghahn Books. Pp. 1-25.

Pauls, H. 2013. Das biopsychosoziale modell - herkunft und aktualität. Resonanzen 1: 15-31.

Rakelmann, G.A. 2005. Process of integration of AIDS into daily life in Botswana: from a foreign to a local disease. Curare 28(2+3): 153-168.

Rowlands, M. and J.-P. Warnier. 1988. Sorcery, power and the modern state in Cameroon. Man, New Series 3(1): 118-132.

Stambach, A. 1999. The rationality debate revisited. Reviews in Anthropology 28: 341-351.

Staugard, F. 1986. Traditional health care in Botswana. In Last, M. and G.L. Chavunduka (eds.). The professionalisation of African medicine. Manchester: Manchester University Press. Pp. 51-86.

Staugard, F. 1989. Traditional medicine in a transitional society: Botswana moving towards the year 2000. Gaborone: Ipelegeng Publishers.

Tabalaka, A.B. 2007. The significance of cultural and religious understanding in the fight against HIV \& AIDS in Botswana. In J.B.R. Gaie and K.M. Sana (eds.) The concept of Botho and HIV \& AIDS in Botswana. Eldoret: Zapf Chancery Publishers Africa. Pp. 61-70.

Thornton, R. 2009. The transmission of knowledge in South African traditional healing. Africa 79(1): 17-34.

Tsing, A. 2010. Worlding the Matsutake diaspora. Or, can Actor-Network Theory experiment with holism? In Otto, T. and N. Bubandt (eds.) Experiments in holism: theory and practice in contemporary anthropology. London: Blackwell. Pp. 47-66.

Ulin, P.R. 1975. The traditional healer of Botswana in a changing society. Botswana Notes and Records 7: 95102.

WHO. 1948. Preamble to the constitution of the World Health Organization as adopted by the International Health Conference. Geneva: World Health Organisation.

WHO. 1990. Report of the consultation on AIDS and traditional medicine: prospects for involving traditional health practitioners. Francistown: World Health Organisation.

WHO 2002. WHO traditional medicine strategy 2002-2005. Geneva: World Health Organisation.

WHRIN 2013. 21th century witchcraft accusation and persecution: Muti murders and human sacrifice: harmful beliefs and practices behind a global crisis in human rights. http://www.whrin.org/wpcontent/uploads/2017/10/2017-UNREPORT-final.pdf. Witchcraft and Human Rights Information Network.

Winkelmann, M. 2013. Shamanism in cross-cultural perspective. International Journal of Transpersonal Studies 31(2): 47-62.

Wiredu, K. 2004. A companion to African philosophy. Oxford: Blackwell. 